\title{
Powers and limitations of open world learning
}

\author{
Experiences from the field of education
}

\author{
Bart Rienties
}

\section{I Introduction}

In September 2014, an interdisciplinary group of 18 researchers from four Faculties at the Open University UK (OU) submitted a (successful) £ 1 million large grant proposal to the Leverhulme Foundation entitled Open World Learning. In its proposal, ${ }^{1}$ the group indicated that

[w] seek support for a programme of $\mathrm{PhD}$ studies to address inclusive approaches to learning across disciplines, integrated by a focus on Open World Learning, for which the OU has a worldwide reputation. Our proposal aims to increase understandings of the complexities of Open World Learning compared to systems and approaches that close rather than open opportunities because of social, geographical, or technical barriers. To do this requires a strong cross-disciplinary approach centred on educational thinking but involving a range of subjects across the University. This cross-disciplinarity means that obtaining funding from domain-specific research councils is not straightforward and there is no targeted programme in this area. The Leverhulme Foundation's Doctoral Scholarship funding, on the other hand, is specifically focussed on cross-disciplinary and complex research topics.

As already described in Chapter 1 (Rienties, Hampel, Scanlon, \& Whitelock, 2022a) and argued throughout this book, learning in the 21st century is undergoing both subtle and radical transformation as a result of the impact of digital, networked technologies (Bond, Zawacki-Richter, \& Nichols, 2019; Ferguson, Jones, \& Scanlon, 2019; Hampel, 2019). Open learning gives unprecedented access to knowledge, information, and education and provides support to learners across the globe (Kizilcec, Saltarelli, Reich, \& Cohen, 2017; Kukulska-Hulme et al., 2021; Weller, 2020). However, it is not the technologies themselves that represent the biggest change, but the opportunities for openness that flow from their thoughtful application, in the form of availability of and access to formal and informal learning (Iniesto, McAndrew, Minocha, \& Coughlan, 2022; Rizvi, Rienties, Kizilcec, \& Rogaten, 2022; Weller, 2020). Without research to gain 
deeper understanding, the changes in learning may exclude the very people who most stand to benefit from them.

Within the Leverhulme Open World Learning programme, 18 scholars from 16 different countries have each contributed to understanding how the enablers and disablers of open world learning might have shifted over time, and how each shift might have had expected and unexpected consequences in open world learning. In this chapter, I critically review some of the key events that have shaped our open world learning in the period 2014-2022, and how this might potentially develop over time in a UK, European, and perhaps global context.

This will by no means be an accurate reflection and review of all facts, perspectives, and contexts. I am acutely aware that experiences and reflections are strongly embedded in one's own context (i.e., working in a top UK distance learning organisation, being a white male academic from Europe, having access to nearly unlimited open world learning opportunities). Nonetheless, I hope that by sharing some of my experiences and reflections of working with leading Leverhulme scholars as well as working with brilliant and state-of-the-art researchers across four Faculties at the OU will help to make sense of how leading institutes like the OU are trailblasing the way to make sense of open world learning.

\subsection{Making sense of open world learning on a macro-meso-micro level}

As conceptually visualised in Figure 2.1, there are both enablers and disablers for open world learning. The fluidity in the 3D shape or space of the open world learning framework highlights that the size and space of open world learning experienced by individual learners and organisations in a particular context, region, or nation might be substantially different from other learners and organisations. Furthermore, the fluidity of the 3D shape and space will inevitably change over

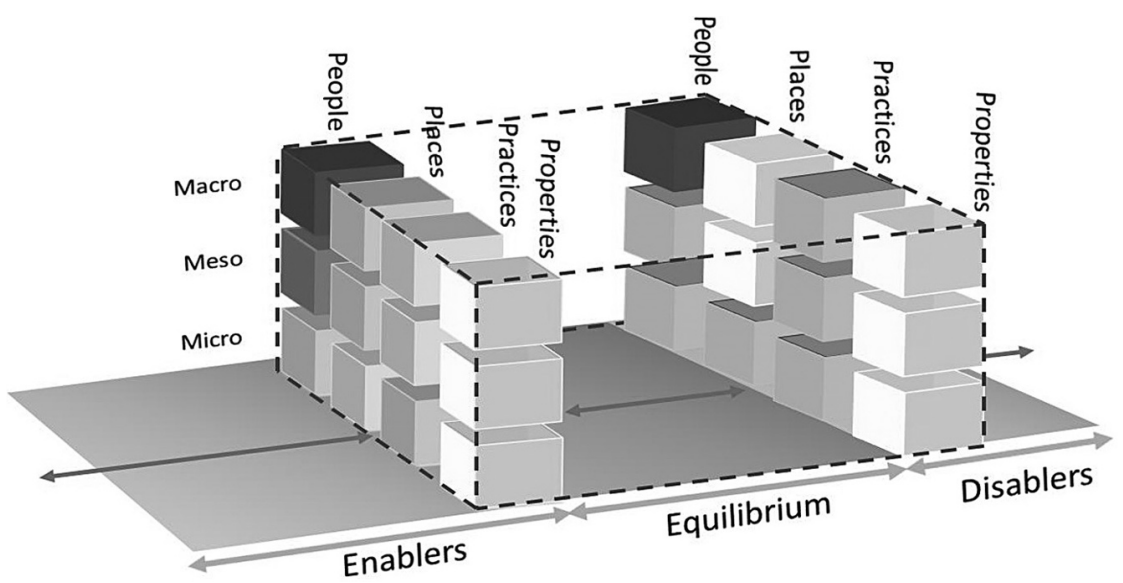

Figure 2.I Open world learning framework (20l4). 
time, making the reach, depth, and breadth of open world learning experiences more or less comprehensive. For example, those learners who have no digital devices, no internet access, and/or who live in countries with very strict access policies might at best only experience open world learning in a limited, match-box manner. In Chapter 10, Mohamud, Buckler, Pitt, and Twining (2022) provide a fascinating account of how providing internet kiosks in Uganda opens up a window of opportunity for open world learning. Other learners who have ubiquitous access, competences, skills, and resources to explore open world learning opportunities and who live in a very open country might have nearly infinite opportunities to enable experience and potentially benefit from open world learning.

At the same time, with the growth in access to online education and the increased competition amongst educational providers and arrival of new commercial entrants into the market, there is also an expansion of the "closed" learning industry (i.e., paid-for by learners and/or organisations) by a range of diversification and growth strategies (e.g., apprenticeships, dual degrees, micro-credentials, short-courses). Obviously, there might be trickle-down effects from closed learning to open learning (e.g., free open short courses as spin-offs from closed courses), as well as opportunities for pathways from open learning into formal degree recognition (e.g., using accreditation of MOOC competition to a formal degree). In other words, the "forces" of the enablers and disablers of open world learning hold each other together in a (temporary) equilibrium, whereby a shift in any of the building blocks might change the equilibrium.

In this conceptual model, I distinguish three levels or spheres of influence on a macro, meso, and micro level. Note that the colouring of these boxes in Figure 2.1 was based upon our joined understanding of the literature and practice within an OU context on each of these levels in 2014. More pronounced darker colours indicate a stronger evidence of experience and research, while lighter boxes represent relatively uncharted research areas.

\subsection{Macro}

On a macro (i.e., regional, national, international, global) level, many things have changed since 2014 and will continue to change. In Chapter 2, I highlight three examples of macro changes in 2014-2022 that inevitably have changed the open word learning spaces for large groups of learners, namely technological change and development, rise of populism, and Brexit. First of all, technological change and development is continuous. For example, in 2014 the first voice-activated virtual assistant in households was introduced (Alexa) by Amazon, whereby in 2020, 22\% of UK households have such a smart speaker in their household (Ofcom, 2020). In 2019, $5 \mathrm{G}$ was launched in the UK giving users over a hundred times faster internet on their phones than in 2012, and uptake in terms of smartphones increased from $61 \%$ in 2014 to $82 \%$ in 2020 (Ofcom, 2020).

While each of the many technologies introduced since 2014 provide their own affordances and limitations, in the last seven years how learners can access online resources has radically accelerated. Indeed, a recent Ofcom (2020) report indicated 
that in the UK during lockdown, on average people spent a record 6 hours and 25 minutes per day watching audiovisual content, often on Smart TVs, and spent on average 4 hours and 2 minutes online, mostly via smartphones (Ofcom, 2020). On the one hand, with most Western jobs being desk-oriented jobs and requiring staff to sit behind a computer, many people have unprecedented access to screens and the internet, thus potentially allowing for opportunities for open world learning. On the other hand, the unprecedented access to screens may negatively impact mental health and wellbeing (Lucassen et al., 2018), and learners' willingness to engage with online learning. Indeed, a lot of organisations (Wellcome Trust, 2020) and the public sector (World Health Organization, 2019) are concerned about the unprecedented access to information and technology, and the increase in screen time. Anecdotally, several CEOs of large tech companies including Microsoft and Snapchat restrict the screen time of their children or even forbid them to use technology.

A second major macro-development is the rise of populism in many Western countries. Narratives around post-truth and \#fakenews are continuing to have a large impact on the perceptions of social media (Ernst, Engesser, Büchel, Blassnig, \& Esser, 2017; Isaak \& Hanna, 2018), and in particular the perceived value of (higher) education (Quinton, 2019) and recognition of experts (Bruggeman et al., 2020; Kubin, Puryear, Schein, \& Gray, 2021). A range of studies have started to explore how people make sense of these complexities and how learners make sense of open knowledge and information. For example, a large-scale study amongst 389 US domestic students by Quinton (2019) showed that students who were more conservative, supported (former) President Trump, and had more negative stereotypes towards international students were significantly less likely to interact with other (international) students. In cross-cultural literature, it is a well-established fact that social interaction between people from different cultures helps to overcome stereotypes and allows people to develop mutual relations and understanding (Jing, Ghosh, Sun, \& Liu, 2020).

Furthermore, in a lab-based study with 308 first-year business students, Knight et al. (2017) found that while most participants indicated to have strong internet searching skills, their actual searching strategies and behaviour indicated that participants mainly used lay health advice website sources rather than academic sources to solve a complex health case. Similarly, using in total 15 studies, Kubin et al. (2021) found that personal experience about a (political) issue, in particular negative experience, was weighted more important than having expertise, knowledge, facts, or data. In other words, while many learners have unprecedented access to knowledge and information, substantial development and training will be needed to ensure that learners can develop strong epistemological skills to make sense of open world learning in this post-truth era.

A third macro trend for the UK in particular is that recent political developments have partially undone 40 years of intensive and open collaboration between European and UK companies, public organisations, and research institutions, and has introduced a range of new barriers in terms of how learners can access data, study, travel, work, etc. In a way, this unexpected macro development went against 
the grain of increased globalisation and open world learning. In part the unexpected referendum result was blamed on social media, and the impact of Cambridge Analytica in particular (Isaak \& Hanna, 2018). In part concerns about international migration and pressure on British identity and values fuelled by (social) media (Gavin, 2018), post-truth, and a divide amongst voters mainly along (higher) education lines (Zhang, 2018) heated opinions. On the one hand, one could argue that open world learning approaches allowed more people to gain access to knowledge, skills, and facts. On the other hand, social media was substantially influenced by political and external parties, and individual (negative) experiences, which may have influenced the referendum result. Perhaps it was not a surprise that the day after asking whether the UK should leave the EU the second most searched question in Google UK was “What is the EU?” (Fung, 2016).

\subsubsection{Meso}

On a meso (i.e., institutional, cross-institutional, cross-discipline) level, education has experienced some radical changes in the last seven years, not only in the UK but worldwide. For example, there is an ever-increasing shift towards consumerism of education (Bragg, 2014; Langan \& Harris, 2019), as well as stronger competition and managerialism within and across institutions (Erickson, Hanna, \& Walker, 2020). Furthermore, there are increased pressures on teachers to include technology in teaching (Bond et al., 2019; Herodotou, Rienties, Boroowa, \& Zdrahal, 2019; Uerz,Volman, \& Kral, 2018; van Leeuwen, 2019), leading to potential burnout and mental stress amongst some teachers (Daniel, 2018), researchers (Wellcome Trust, 2020), and students (Houghton \& Anderson, 2017). All these trends were accelerated and exacerbated by the COVID-19 pandemic, where teachers suddenly had to become experts in blended/online teaching overnight (Crawford et al., 2020; Naffi, 2020; Reinholz, Stone-Johnstone, White, Sianez, \& Shah, 2020).

Another meso change is the increased focus on Equality, Diversity and Inclusion (EDI) in (higher) education. In part this increased focus on EDI is fuelled by the \#metoo and \#blacklivesmatter movements that have a macro and meso impact, as well as a range of studies highlighting substantial inequality in opportunity in education (e.g., Bhopal \& Henderson, 2021; Lucassen et al., 2018; Nguyen, Rienties, \& Richardson, 2020a; Richardson, Mittelmeier, \& Rienties, 2020). For example, in Chapter 15, Iniesto and Hillaire (2022) indicate that despite efforts by MOOC providers to make their materials accessible, in practice this often falls short for learners with accessibility needs. Similarly, in Chapter 8, Rizvi et al. (2022) show that despite best intentions, MOOC learning activities are not necessarily fit for purpose for some geo-cultural groups of learners, as the (Western) learning designs of MOOCs do not necessarily fit with their preferred learning approach.

Indeed, a range of institutional and cross-institutional initiatives such as Athena Swan and Race Equality Charter have started to address some of these inequalities of opportunities, including explicit requirements for institutions to report on how they are addressing these inequalities. However, there are substantial tensions in 
terms of prioritising which part of EDI to focus on first, as argued by Bhopal and Henderson (2021, p. 167) "[w]hile institutions can claim to be working on structural inequality by focusing time, resources and attention on gender equality, there is little or no imperative to shift the focus to uncomfortable conversations about race and racism in the academy". Both the macro and meso changes in the last seven years have had a substantial impact on the micro level of open world learning.

\subsubsection{Micro}

Finally, on a micro (within institution, module, student) level, several large changes have occurred that have influenced how educators design courses and how learners learn. For example, with the omnipresence of technology and mobile devices in the classroom, the way students learn and interact with others is rapidly changing education (Kukulska-Hulme et al., 2021; Srisontisuk, 2022). For example, in the OU, while many courses in 2014 had several offline and print-based learning resources, in 2021, nearly all resources are primarily available online (Nguyen, Rienties, \& Whitelock, 2020b). Similarly, with the increased availability of free online resources, MOOCs, and other learning opportunities, students and teachers have unprecedented access to knowledge and information (Conde Gafaro, 2022).

A large change on a micro-level is the access to data and learning analytics data in particular. While in 2014 mostly institutions were storing some data for retrospective reporting for accreditation processes and government bodies, an increasing number of teachers and students have gained (near) real-time access to learning and learner data. For example, Herodotou et al. (2020) analysed how the predictive learning analytics tool OU Analyse was accessed by 1159 unique teachers and reached 23,180 students in 231 undergraduate courses in the last four years, and found substantial different adoption patterns between teachers. These in part were explained by how Faculties engaged with predictive learning analytics, how they encouraged teachers as "champions", as well as teachers' digital literacy and their conceptions about teaching online. In Chapter 13, Hillaire, Rienties, Fenton-O'Creevy, Zdrahal, and Tempelaar (2022) show that based upon online chat discourse between 1251 business undergraduate students, a student-sourced sentiment analysis tool can be developed that can accurately predict emotions in written text.

\subsection{The 4P approach of Open World Learning}

As indicated in Figure 2.1, beyond the macro-meso-micro levels, the 4P approach distinguishes between four important inter-related themes that may influence the enablers and disablers of open world learning: people, places, practices, and properties. Given the nature of open world learning, some of these enablers or disablers of learning might influence the four themes differently. 


\subsection{People}

In terms of the theme people accessibility needs (Iniesto et al., 2022), socioeconomic factors (Rizvi et al., 2022), and personal learner characteristics such as age (Iwaniec-Thompson, 2022), ethnicity (Nguyen, Rienties et al., 2020b), gender (Richardson et al., 2020), and learning dispositions (Tempelaar, Rienties, \& Nguyen, 2021) might influence whether people can benefit from open-world learning. For example, in Chapter 7, Rets et al. (2022) show that Open Educational Resources (OERs) could be made more accessible for non-native English speakers by decreasing their complexity level by text simplification. In Chapter 14 Nguyen, Rienties and Whitelock (2022) shows that teachers make complex decisions when designing closed and open world learning designs, which in part are influenced by their own conceptions of teaching, as well as the culture of the discipline in which they work.

\subsubsection{Places}

Secondly, places where people work or live might substantially impact on how they get access to open world learning opportunities. For example, Facebook restricted access to news sites in Australia in February 2021, thereby limiting people's access to knowledge and information. In some countries like Myanmar or Belarus, Facebook and other social media sites have been taken offline during social unrest, while in other countries certain topics are censored or even completely barred. Beyond actively restricting content and access to open world learning, even when learning activities are openly available this does not necessarily imply that users will universally make sense of them in the same way. For example, in Chapter 8, Rizvi et al. (2022) show in two studies that MOOCs are not necessarily culturally inclusive, based upon engagement patterns by 49,582 learners in ten Futurelearn MOOCs. In Chapter 4,Vogiatzis et al. (2022) explore how WhatsApp was used by German-language learners on the move, while in Chapter 10, Mohamud et al. (2022) show how internet kiosks in one particular context of Uganda raised some culturally specific opportunities and concerns.

\subsubsection{Practices}

Thirdly, the practices people and institutions are surrounded by might influence how they engage with open world learning. Although sometimes we seem to live in a global village, the way that education is shaped in countries is mostly determined by policy makers and stakeholders on a national level, whereby consistently substantial differences in practices are noticed on a regional, national, and geocultural level (Kizilcec et al., 2017; OECD, 2018; Rizvi et al., 2022). Also, girls are particularly likely to be left behind (Girls' Education Challenge, 2021). An emerging body of research has shown that for example while MOOCs are accessible across the globe, some nations and geo-cultural regions are more likely to benefit from these open world learning opportunities than others. Indeed, accessibility policies of MOOCs are framed and shaped by local and national practices and 
policies as evidenced in Chapter 9 (Iniesto et al., 2022). In the context of financial sectors, in Chapter 17, Chaudhari, Littlejohn, and Cross (2022) show that how finance professionals cope with uncertainty and make use of technologies is nested within their practice.

\subsubsection{Properties}

Finally, properties of open world learning technologies and data will substantially influence the affordances and limitations of how people make sense of open world learning. As illustrated in Figure 2.1, there was a relative paucity of research in 2014 on how properties of data and practices within open world learning might enable or thwart learning. For example, the OU was the first institution to introduce an ethics policy on the use of data with learning analytics (Open University UK, 2014). In Chapter 11, Korir et al. (2022) show that most UK learners are now reasonably comfortable to share their data with higher education institutions, while initially some authors reported concerns about privacy and sharing of data. In Chapter 12, Nguyen et al. (2022) show that OU teachers make substantial use of student engagement data to determine how they design online courses. In particular how they balance assessment, interactive, and communicative learning activities seems to significantly impact student engagement, retention and satisfaction. At the same time, with the triangulation of more and more data and as Artificial Intelligence is becoming more intertwined in education (Rienties, Køhler Simonsen, \& Herodotou, 2020), there are substantial concerns about how algorithms are potentially making decisions that could influence behaviour and performance of learners (Baker \& Hawn, 2021; Prinsloo \& Slade, 2017).

\subsection{Discussion and moving forward}

In this book, each of the chapters will explore how the enablers and disablers of open world learning may have shifted over time. As indicated in Table 2.1, almost all chapters focus on the people theme of open world learning. This book brings together insights from 387,134 learners and educators in 136 unique learning contexts, from short lab-exercises (Hillaire et al., 2022; Rets et al., 2022), in-class experiments (Anastasiou, 2022), online experiments (Korir, 2022), to longer intensive blended and online courses (Conde Gafaro, 2022; Vogiatzis et al., 2022) and MOOCs (Chua, 2022; Rizvi et al., 2022). Many of the chapters do this mostly on a micro level, focussed on learners, teachers and technologies in one particular context or setting. This is important as a lot of macro studies have already been written on the affordances and limitations of open world learning. There is a dire need to conduct high-quality evidence-based research on the meso and micro level of learners and teachers of what works, and what does not, and why.

The second important theme that will be discussed in this book is the practices in which learners and teachers find themselves. As context is everything in education, unpacking how practice influences learners and teachers to make sense of open world learning will help you, the reader, to use these insights for your own 
Table 2.I Levels and 4Ps of open world learning discussed in this book

\begin{tabular}{|c|c|c|c|c|c|c|}
\hline Authors & Chapter & Level & People & Places & Practices & Properties \\
\hline \multicolumn{7}{|c|}{ Part I Learners and the power of language in an Open World } \\
\hline Anastasiou & $\begin{array}{l}03 \text { Digital stories in science: The role of story } \\
\text { sequencing }\end{array}$ & Micro & $\checkmark$ & & & \\
\hline $\begin{array}{l}\text { Vogiatzis, Charitonos, } \\
\text { Giaxoglou \& Lewis }\end{array}$ & $\begin{array}{l}04 \text { Can WhatsApp facilitate interaction? A case } \\
\text { study of adult language learning }\end{array}$ & Micro & $\checkmark$ & $\checkmark$ & & \\
\hline Conde Gaforo & $\begin{array}{l}05 \text { First steps towards self-regulated learning: } \\
\text { Setting goals in MOOCs }\end{array}$ & Micro & $\checkmark$ & & $\checkmark$ & \\
\hline Chua & $\begin{array}{l}06 \text { Discourse practices in MOOC discussions: A } \\
\text { corpus linguistic approach }\end{array}$ & Micro & $\checkmark$ & & & $\checkmark$ \\
\hline $\begin{array}{l}\text { Rets, Stickler, } \\
\text { Coughlan \& Astruc }\end{array}$ & $\begin{array}{l}07 \text { Simplification of open educational resources in } \\
\text { English: Its effect on text processing of English } \\
\text { learners }\end{array}$ & Micro & $\checkmark$ & & & $\checkmark$ \\
\hline $\begin{array}{l}\text { Rizvi, Rienties, } \\
\text { Rogaten \& Kizilcec }\end{array}$ & $\begin{array}{l}08 \text { Culturally adaptive learning design: A mixed- } \\
\text { methods study of cross-cultural learning design } \\
\text { preferences in MOOCs }\end{array}$ & $\begin{array}{l}\text { Mesol } \\
\text { micro }\end{array}$ & $\checkmark$ & $\checkmark$ & $\checkmark$ & \\
\hline \multicolumn{7}{|c|}{ Part II Innovative technologies in an Open World } \\
\hline $\begin{array}{l}\text { Iniesto, McAndrew, } \\
\text { Minocha \& } \\
\text { Coughlan }\end{array}$ & $\begin{array}{l}09 \text { Accessibility in MOOCs: The stakeholders' } \\
\text { perspectives }\end{array}$ & $\begin{array}{l}\text { Meso/ } \\
\text { micro }\end{array}$ & $\checkmark$ & & $\checkmark$ & $\checkmark$ \\
\hline $\begin{array}{l}\text { Mohamud, Buckler, } \\
\text { Pitt \& Twining }\end{array}$ & $\begin{array}{l}\text { I0 Internet kiosks in Uganda: A window of } \\
\text { opportunities? }\end{array}$ & $\begin{array}{l}\text { Mesol } \\
\text { micro }\end{array}$ & $\checkmark$ & $\checkmark$ & $\checkmark$ & \\
\hline $\begin{array}{l}\text { Korir, Slade, Holmes } \\
\text { \& Rienties }\end{array}$ & $\begin{array}{l}\text { I Eliciting students' preferences for the use of } \\
\text { their data for learning analytics: A } \\
\text { crowdsourcing approach }\end{array}$ & Micro & $\checkmark$ & & & $\checkmark$ \\
\hline $\begin{array}{l}\text { Hall, Herodotou \& } \\
\text { lacovides }\end{array}$ & $\begin{array}{l}\text { I2 Measuring player creativity in digital } \\
\text { entertainment games using the creativity in } \\
\text { gaming scale }\end{array}$ & Micro & $\checkmark$ & & & \\
\hline
\end{tabular}


Table 2.I (Continued)

\begin{tabular}{|c|c|c|c|c|c|c|}
\hline Authors & Chapter & Level & People & Places & Practices & Properties \\
\hline $\begin{array}{l}\text { Hillaire, Rienties, } \\
\text { Fenton-O'Creevy, } \\
\text { Zdrahal \& } \\
\text { Tempelaar }\end{array}$ & $\begin{array}{l}\text { I Incorporating student opinion into opinion } \\
\text { mining: A student-sourced sentiment analysis } \\
\text { classifier }\end{array}$ & Micro & $\checkmark$ & & & $\checkmark$ \\
\hline
\end{tabular}

\section{Part III Educators and inclusive practice in an Open World}

Nguyen, Rienties \&

Whitelock

Iniesto \& Hillaire

Srisontisuk

Chaudhari, Littlejohn

$$
\text { \& Cross }
$$

Iwaniec-Thompson
14 Informing learning design in online education using learning analytics of student engagement 15 UDL and its implications in MOOC

accessibility evaluation

16 Practitioner's perspective on young children's use of mobile technology

17 Antecedents and consequences of uncertainties perceived by finance professionals

18 The identity trajectories of older academics:

Workplace affordances and individual subjectivities

Note: that all the reported studies included in this book went through formal Human Research Ethics Committee at the Open University UK, and received approval.

\begin{tabular}{|c|c|c|}
\hline Meso & $\checkmark$ & $\checkmark$ \\
\hline Meso & & $\checkmark$ \\
\hline $\begin{array}{l}\text { Mesol } \\
\text { micro }\end{array}$ & $\checkmark$ & $\checkmark$ \\
\hline $\begin{array}{l}\text { Mesol } \\
\text { micro }\end{array}$ & $\checkmark$ & $\checkmark$ \\
\hline $\begin{array}{l}\text { Mesol } \\
\text { micro }\end{array}$ & $\checkmark$ & $\checkmark$ \\
\hline
\end{tabular}

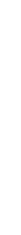


practice. Finally, places and properties will be explored in several Chapters. In Chapter 19 (Rienties, Hampel, Scanlon, \& Whitelock, 2022b), we will bring together all these findings and insights and discuss how they have shifted our understanding of open world learning.

\section{Note}

1 https://iet.open.ac.uk/projects/owl

\section{References}

Anastasiou, P. (2022). Digital stories in science: The role of story sequencing. In B. Rienties, R. Hampel, E. Scanlon, \& D. Whitelock (Eds.), Open World Learning: Research, Innovation and the Challenges of High-Quality Education (pp. 29-43). London: Routledge.

Baker, R. S., \& Hawn, A. (2021). Algorithmic Bias in Education. doi: 10.35542/osf.io/pbmvz.

Bhopal, K., \& Henderson, H. (2021). Competing inequalities: gender versus race in higher education institutions in the UK. Educational Review, 73(2), 153-169. doi: 10.1080/ 00131911.2019 .1642305

Bond, M., Zawacki-Richter, O., \& Nichols, M. (2019). Revisiting five decades of educational technology research: A content and authorship analysis of the British Journal of Educational Technology. British Journal of Educational Technology, 50(1), 12-63. doi: $10.1111 /$ bjet. 12730

Bragg, S. (2014). Education, 'consumerism' and 'personalisation'. British Journal of Sociology of Education, 35(2), 308-315. doi: 10.1080/01425692.2014.881054

Bruggeman, B., Tondeur, J., Struyven, K., Pynoo, B., Garone, A., \& Vanslambrouck, S. (2020). Experts speaking: Crucial teacher attributes for implementing blended learning in higher education. The Internet and Higher Education, 100772. doi: 10.1016/j.iheduc.2020.100772

Chaudhari, V., Littlejohn, A., \& Cross, S. (2022). Antecedents and consequences of uncertainties perceived by finance professionals. In B. Rienties, R. Hampel, E. Scanlon, \& D. Whitelock (Eds.), Open World Learning: Research, Innovation and the Challenges of HighQuality Education (pp. 237-249). London: Routledge.

Chua, S. M. (2022). Discourse practices in MOOC discussions: A corpus linguistic approach. In B. Rienties, R. Hampel, E. Scanlon, \& D. Whitelock (Eds.), Open World Learning: Research, Innovation and the Challenges of High-Quality Education (pp. 76-88). London: Routledge.

Conde Gafaro, B. (2022). First steps towards self-regulated learning: Setting goals in MOOCs. In B. Rienties, R. Hampel, E. Scanlon, \& D.Whitelock (Eds.), Open World Learning: Research, Innovation and the Challenges of High-Quality Education (pp. 63-75). London: Routledge.

Crawford, J., Butler-Henderson, K., Rudolph, J., Malkawi, B., Glowatz, M., Burton, R., ... Lam, S. (2020). COVID-19: 20 countries' higher education intra-period digital pedagogy responses. Journal of Applied Learning \& Teaching, 3(1), 1-20.

Daniel, B. K. (2018). Contestable professional academic identity of those who teach research methodology. International Journal of Research \& Method in Education, 41(5), 548-561. doi: 10.1080/1743727X.2017.1369510

Erickson, M., Hanna, P., \& Walker, C. (2020). The UK higher education senior management survey: a statactivist response to managerialist governance. Studies in Higher Education, 1-18. doi: 10.1080/03075079.2020.1712693

Ernst, N., Engesser, S., Büchel, F., Blassnig, S., \& Esser, F. (2017). Extreme parties and populism: an analysis of Facebook and Twitter across six countries. Information, Communication E Society, 20(9), 1347-1364. doi: 10.1080/1369118X.2017.1329333 
Ferguson, R., Jones, A., \& Scanlon, E. (2019). Educational visions: The lessons from 40 years of innovation. London: Ubiquity Press.

Fung, B. (2016). The British are frantically Googling what the E.U. is, hours after voting to leave it. The Washington Post. Retrieved from https://www.washingtonpost.com/news/ the-switch/wp/2016/06/24/the-british-are-frantically-googling-what-the-eu-ishours-after-voting-to-leave-it/

Gavin, N. T. (2018). Media definitely do matter: Brexit, immigration, climate change and beyond. The British Journal of Politics and International Relations, 20(4), 827-845. doi: 10.1177/1369148118799260

Girls' Education Challenge. (2021). Leave no girl behind. Retrieved 17 April 2021, from https://girlseducationchallenge.org/

Hampel, R. (2019). Disruptive Technologies and the Language Classroom. Cham: Springer.

Herodotou, C., Rienties, B., Boroowa, A., \& Zdrahal, Z. (2019). A large-scale implementation of predictive learning analytics in higher education: the teachers' role and perspective. Educational Technology Research Devevelopment, 67, 1273-1306. doi: 10.1007/s11423-01909685-0

Herodotou, C., Rienties, B., Hlosta, M., Boroowa, A., Mangafa, C., \& Zdrahal, Z. (2020). The scalable implementation of predictive learning analytics at a distance learning university: Insights from a longitudinal case study. The Internet and Higher Education, 45, 100725. doi: 10.1016/j.iheduc.2020.100725

Hillaire, G., Rienties, B., Fenton-O'Creevy, M., Zdrahal, Z., \& Tempelaar, D. (2022). Incorporating student opinion into opinion mining: A student-sourced sentiment analysis classifier. In B. Rienties, R. Hampel, E. Scanlon, \& D. Whitelock (Eds.), Open World Learning: Research, Innovation and the Challenges of High-Quality Education (pp. 171-186). London: Routledge.

Houghton, A.-M., \& Anderson, J. (2017). Embedding mental wellbeing in the curriculum: maximising success in higher education. York: Higher Education Academy.

Iniesto, F., \& Hillaire, G. (2022). UDL and its implications in MOOC accessibility evaluation. In B. Rienties, R. Hampel, E. Scanlon, \& D. Whitelock (Eds.), Open World Learning: Research, Innovation and the Challenges of High-Quality Education (pp. 208-224). London: Routledge.

Iniesto, F, McAndrew, P., Minocha, S., \& Coughlan, T. (2022). Accessibility in MOOCs:The stakeholders' perspectives. In B. Rienties, R. Hampel, E. Scanlon, \& D. Whitelock (Eds.), Open World Learning: Research, Innovation and the Challenges of High-Quality Education (pp. 119-130). London: Routledge.

Isaak, J., \& Hanna, M. J. (2018). User Data Privacy: Facebook, Cambridge Analytica, and Privacy Protection. Computer, 51(8), 56-59.

Iwaniec-Thompson, G. (2022). The identity trajectories of older academics: Workplace affordances and individual subjectivities. In B. Rienties, R. Hampel, E. Scanlon, \& D. Whitelock (Eds.), Open World Learning: Research, Innovation and the Challenges of HighQuality Education (pp. 250-263). London: Routledge.

Jing, X., Ghosh, R., Sun, Z., \& Liu, Q. (2020). Mapping global research related to international students: a scientometric review. Higher Education. doi: 10.1007/s10734-019-00489-y

Kizilcec, R., Saltarelli, A. J., Reich, J., \& Cohen, G. L. (2017). Closing global achievement gaps in MOOCs. Science, 355(6322), 251-252. doi: 10.1126/science.aag2063

Knight, S., Rienties, B., Littleton, K., Mitsui, M., Tempelaar, D. T., \& Shah, C. (2017). The relationship of (perceived) epistemic cognition to interaction with resources on the internet Computers in Human Behavior, 73(August 2017), 507-518. 
Korir, M., Slade, S., Holmes, W., \& Rienties, B. (2022). Eliciting students' preferences for the use of their data for learning analytics: A crowdsourcing approach. In B. Rienties, R. Hampel, E. Scanlon, \& D. Whitelock (Eds.), Open World Learning: Research, Innovation and the Challenges of High-Quality Education (pp. 144-156). London: Routledge.

Kubin, E., Puryear, C., Schein, C., \& Gray, K. (2021). Personal experiences bridge moral and political divides better than facts. Proceedings of the National Academy of Sciences, 118(6), e2008389118. doi: 10.1073/pnas.2008389118

Kukulska-Hulme, A., Bossu, C., Coughlan, T., Ferguson, R., FitzGerald, E., Gaved, M., ... Zhang, S. (2021). Innovating Pedagogy 2021 Open University Innovation Report 9. Milton Keynes:The Open University.

Langan, A. M., \& Harris, W. E. (2019). National student survey metrics: where is the room for improvement? Higher Education, 78(6), 1075-1089. doi: 10.1007/s10734-019-00389-1

Lucassen, M., Samra, R., Iacovides, I., Fleming, T., Shepherd, M., Stasiak, K., \& Wallace, L. (2018). How LGBT+Young People Use the Internet in Relation to Their Mental Health and Envisage the Use of e-Therapy: Exploratory Study. JMIR Serious Games 2018:6(4), e11249. doi: 10.2196/11249.

Mohamud, K., Buckler, A., Pitt, B., \& Twining, P. (2022). Internet kiosks in Uganda: A window of opportunities? In B. Rienties, R. Hampel, E. Scanlon, \& D. Whitelock (Eds.), Open World Learning: Research, Innovation and the Challenges of High-Quality Education (pp. 131-143). London: Routledge.

Naffi, N. (2020). Disruption in and by Centres for Teaching and Learning During the COVID-19 Pandemic Leading the Future of Higher Ed. Canada: Universite Laval.

Nguyen, Q., Rienties, B., \& Whitelock, D. (2022). Informing learning design in online education using learning analytics of student engagement. In B. Rienties, R. Hampel, E. Scanlon, \& D.Whitelock (Eds.), Open World Learning: Research, Innovation and the Challenges of High-Quality Education (pp. 189-209). London: Routledge.

Nguyen, Q., Rienties, B., \& Richardson, J.T.E. (2020a). Learning analytics to uncover inequality in behavioural engagement and academic attainment in a distance learning setting. Assessment and Evaluation in Higher Education, 45(4), 594-606. doi: 10.1080/02602938.2019.1679088

Nguyen, Q., Rienties, B., \& Whitelock, D. (2020b). A Mixed-Method Study of How Instructors Design for Learning in Online and Distance Education. Journal of Learning Analytics, 7(3), 64-78. doi: 10.18608/jla.2020.73.6

OECD. (2018). The future of education and skills. Education 2030. Paris: OECD.

Ofcom. (2020). Online nation 2020 report.

Open University UK. (2014). Ethical use of Student Data for Learning Analytics Policy. Retrieved 23 June 2016,2016, from http://www.open.ac.uk/students/charter/essential-documents/ ethical-use-student-data-learning-analytics-policy

Prinsloo, P., \& Slade, S. (2017). Ethics and Learning Analytics: Charting the (Un)Charted. In C. Lang, G. Siemens, A. F. Wise, \& D. Gasevic (Eds.), Handbook of learning analytics (pp. 49-57). Sydney: Society for Learning Analytics Research.

Quinton, W. J. (2019). Unwelcome on campus? Predictors of prejudice against international students. Journal of Diversity in Higher Education, 12(2), 156-169. doi: 10.1037/dhe0000091

Reinholz, D. L., Stone-Johnstone, A., White, I., Sianez, L. M., \& Shah, N. (2020). A Pandemic Crash Course: Learning to Teach Equitably in Synchronous Online Classes. CBE-Life Sciences Education, 19(4), ar60. doi: 10.1187/cbe.20-06-0126

Rets, I., Stickler, U., Coughlan, T., \& Astruc, L. (2022). Simplification of open educational resources in English: Its effect on text processing of English learners In B. Rienties, R. Hampel, E. Scanlon, \& D. Whitelock (Eds.), Open World Learning: Research, Innovation and the Challenges of High-Quality Education (pp. 89-102). London: Routledge. 
Richardson, J.T. E., Mittelmeier, J., \& Rienties, B. (2020). The role of gender, social class and ethnicity in participation and academic attainment in UK higher education: an update. Oxford Review of Education, 46(3), 346-362. doi: 10.1080/03054985.2019.1702012

Rienties, B., Hampel, R., Scanlon, E., \& Whitelock, D. (2022a). Introduction to open world learning: What works? In B. Rienties, R. Hampel, E. Scanlon, \& D. Whitelock (Eds.), Open World Learning: Research, Innovation and the Challenges of High-Quality Education (pp. 1-12). London: Routledge.

Rienties, B., Hampel, R., Scanlon, E., \& Whitelock, D. (2022b). Reflecting on the main findings and practical applications. In B. Rienties, R. Hampel, E. Scanlon, \& D. Whitelock (Eds.), Open World Learning: Research, Innovation and the Challenges of High-Quality Education (pp. 264-272). London: Routledge.

Rienties, B., Køhler Simonsen, H., \& Herodotou, C. (2020). Defining the Boundaries Between Artificial Intelligence in Education, Computer-Supported Collaborative Learning, Educational Data Mining, and Learning Analytics: A Need for Coherence. Frontiers in Education, 5(128). doi: 10.3389/feduc.2020.00128

Rizvi, S., Rienties, B., Kizilcec, R., \& Rogaten, J. (2022). Culturally adaptive learning design: A mixed-method study of cross-cultural learning design preferences in MOOCs In B. Rienties, R. Hampel, E. Scanlon, \& D. Whitelock (Eds.), Open World Learning: Research, Innovation and the Challenges of High-Quality Education (pp. 103-116). London: Routledge.

Srisontisuk, P. (2022). Practitioner's perspective on young children's use of mobile technology. In B. Rienties, R. Hampel, E. Scanlon, \& D. Whitelock (Eds.), Open World Learning: Research, Innovation and the Challenges of High-Quality Education (pp. 225-236). London: Routledge.

Tempelaar, D.T., Rienties, B., \& Nguyen, Q. (2021). The contribution of dispositional learning analytics to precision education. Journal of Educational Technology and Society, 24(1), 109-122.

Uerz, D., Volman, M., \& Kral, M. (2018). Teacher educators' competences in fostering student teachers' proficiency in teaching and learning with technology: An overview of relevant research literature. Teaching and Teacher Education, 70, 12-23. doi:10.1016/j. tate.2017.11.005

van Leeuwen,A. (2019). Teachers' perceptions of the usability of learning analytics reports in a flipped university course: when and how does information become actionable knowledge? Educational Technology Research and Development, 67(5), 1043-1064. doi: 10.1007/ s11423-018-09639-y

Vogiatzis, D., Charitonos, K., Giaxoglou, K., \& Lewis, T. (2022). Can WhatsApp facilitate interaction? A case study of adult language learning. In B. Rienties, R. Hampel, E. Scanlon, \& D. Whitelock (Eds.), Open World Learning: Research, Innovation and the Challenges of HighQuality Education (pp. 44-62). London: Routledge.

Wellcome Trust. (2020). What researchers think about the culture they work In. London:Wellcome Trust.

Weller, M. (2020). Open and free access to education for all. In D. Burgos (Ed.), Radical Solutions and Open Science (pp. 1-15). Springer, Singapore.

World Health Organization. (2019). Guidelines on physical activity, sedentary behaviour and sleep for children under 5 years of age. Geneva: World Health Organization.

Zhang, A. (2018). New Findings on Key Factors Influencing the UK's Referendum on Leaving the EU. World Development, 102, 304-314. doi:10.1016/j.worlddev.2017. 07.017 